University of Windsor

Scholarship at UWindsor

$12-5-2016$

\title{
Chickadees Faced with Unpredictable Food Increase Fat Reserves but Certain Components of Their Immune Function Decline
}

Emily A. Cornelius

François Vézina

Lyette Regimbald

Fanny Hallot

Magali Petit

See next page for additional authors

Follow this and additional works at: https://scholar.uwindsor.ca/biologypub

Part of the Biology Commons

\section{Recommended Citation}

Cornelius, Emily A.; Vézina, François; Regimbald, Lyette; Hallot, Fanny; Petit, Magali; and Love, Oliver P., "Chickadees Faced with Unpredictable Food Increase Fat Reserves but Certain Components of Their Immune Function Decline" (2016). Physiological and Biochemical Zoology, 90, 2, 190-200.

https://scholar.uwindsor.ca/biologypub/124

This Article is brought to you for free and open access by the Department of Biological Sciences at Scholarship at UWindsor. It has been accepted for inclusion in Biological Sciences Publications by an authorized administrator of Scholarship at UWindsor. For more information, please contact scholarship@uwindsor.ca. 


\section{Authors}

Emily A. Cornelius, François Vézina, Lyette Regimbald, Fanny Hallot, Magali Petit, and Oliver P. Love 


\section{Chickadees Faced with Unpredictable Food Increase Fat Reserves but Certain Components of Their Immune Function Decline ${ }^{\star}$}

\author{
Emily A. Cornelius ${ }^{1, \dagger}$ \\ François Vézina ${ }^{2}$ \\ Lyette Regimbald ${ }^{2}$ \\ Fanny Hallot ${ }^{2}$ \\ Magali Petit ${ }^{2}$ \\ Oliver P. Love ${ }^{3}$ \\ William H. Karasov ${ }^{1}$ \\ ${ }^{1}$ Department of Forest and Wildlife Ecology, University of \\ Wisconsin, Madison, Wisconsin 53706; ${ }^{2}$ Département de \\ Biologie, Chimie, et Géographie, Université du Québec à \\ Rimouski, Rimouski, Quebec G5L 3A1, Canada; ${ }^{3}$ Department \\ of Biological Sciences and Great Lakes Institute for \\ Environmental Research, University of Windsor, Windsor, \\ Ontario N9B 3P4, Canada
}

Accepted 10/17/2016; Electronically Published 12/5/2016

\begin{abstract}
In winter, temperate resident birds are often faced with periodic low natural food availability. This reduction or unpredictability in resource availability might then have a negative impact on immune function, given that immune system support is highly resource dependent. We investigated the balance between energetic and immune management in captive black-capped chickadees (Poecile atricapilus) by manipulating the predictability of resources. The control group received food ad lib. every day, while the experimental group received a reduced amount of food on random days and food ad lib. on all other days. We measured two key metrics of energetic management (body and fat mass) as well as a suite of immune system components. Compared with control birds, experimental birds maintained significantly higher total body and fat mass, had lower acute phase protein concentrations, and had decreased body temperature and lost more body mass during the fever response following injection with
\end{abstract}

\footnotetext{
${ }^{*}$ This paper is based on a talk given at the ICCPB 2015 symposium, "Phenotypic Flexibility of Energetics in a Seasonal World," which was sponsored by the Division of Comparative Physiology and Biochemistry, SICB. Marek Konarzewski, David Swanson, and Michal S. Wojciechowski were guest editors for this collection.

†Corresponding author; e-mail: ecornelius@wisc.edu.

Correction: This article was reposted on January 13, 2017. Changes were made to values in the "Complement Lysis," "Responses in Energy Budgeting," and "Responses in Immune Function" sections and to table 2 and figure 5. An erratum appears in this issue.
}

Physiological and Biochemical Zoology 90(2):190-200. 2017. (C) 2016 by The University of Chicago. All rights reserved. 1522-2152/2017/9002-6020\$15.00. DOI: $10.1086 / 689913$ lipopolysaccharides. Interestingly, birds in both groups had similar levels of complement lysis, delayed-type hypersensitivity response (phytohemagglutinin), and primary antibody production (keyhole limpet hemocyanin). This experiment demonstrates that black-capped chickadees strategically increase their fat mass in response to decreased food availability and that this might allow the birds to maintain most of the immune system unaltered, except some of the most costly immune components.

Keywords: food unpredictability, immune function, body condition, fat, complement, haptoglobin, black-capped chickadee.

\section{Introduction}

In winter or during an extreme weather event, natural food availability can be unpredictable or animals might not be able to forage for resources, which typically causes declines in body mass (Acquarone et al. 2002; Cucco et al. 2002). In this situation, a simple explanation for the mass loss is a passive thermodynamic response to the energy imbalance caused by lower energy intake. Alternatively, in some animals, the periodic energy imbalance induces an active response whereby they strategically adjust to unpredictable food resources with an increase in fat and body mass as a hedge against energy imbalance (Witter et al. 1995; Houston et al. 2007).

The idea of strategic increases in fattening has been proposed by many to explain variation in winter body mass of small temperate resident passerines (McNamara and Houston 1990; Houston and McNamara 1993; Witter et al. 1995). Descriptive studies have shown that resident birds tend to be the heaviest during the harshest periods of winter, when food availability might be low (Lehikoinen 1987; Witter et al. 1995; Cooper 2007). This increase in lipid stores is thought to provide a buffer of protection when birds might not be able to adequately forage or find enough daily resources. Nevertheless, while this strategic fattening is typically thought of as a benefit, sometimes there are associated costs, including increased energy expenditure and thus metabolic rate (Witter and Cuthill 1993) and also risk of predation (Witter et al. 1995).

To our knowledge, only a few studies in birds examined immune responses to unpredictable food resources, that is, periodic energy imbalances. For example, when food abundance and predictability were experimentally altered, magpies (Pica pica) decreased mass and had decreased hematocrit levels and a decreased response to phytohemagglutinin (PHA; Cucco et al. 2002). The same response was noted in the hooded crow (Corvis cornix; Acquarone et al. 2002). However, to date, immune func- 
tion has not been studied in birds that exhibited an anticipatory increase in fat and body mass as a hedge against energy imbalance, and relatively few features of immune function have been studied in birds exposed to unpredictable resources (but see Buehler et al. 2008; Pap et al. 2010). On the basis of previous research on food unpredictability in birds and the idea of strategic fattening, several responses are possible.

If birds decline in body mass in response to unpredictable food, then the variability in food resources might have a negative impact on immune function, as might occur if adequate energy and nutrients for mounting an immune response are not acquired (Martin et al. 2008). In birds, there are a number of examples of persistent energy imbalance (intake < expenditure) causing declines in immune function. These include foodrestricted sand martins (Riparia riparia) with a delayed-type hypersensitivity immune response to PHA (Brzęk and Konarzewski 2007) and house sparrow nestlings (Passer domesticus) with a reduced acute phase response compared with control birds fed ad lib. (Killpack et al. 2015).

If birds respond strategically to unpredictable food resources with an increase in fat and body mass as a hedge against energy imbalance, one possibility is that immune functions might be maintained because the energy and nutrients for mounting immune responses have been adequately sequestered. However, because the sequestration of energy and nutrients might itself come at a cost to other biological functions, declines in immune functions might occur as a trade-off between using resources for energy balance or maintaining immune function (Lochmiller and Deerenberg 2000; i.e., a trade-off between maintenance of the somatic state and the immune system). Because various immune functions are thought to be associated with quite different energetic costs, the situation might be complex, with some immune components declining whereas others are unaltered (Klasing 2004; Lee 2006). This is one reason to study responses of a number of immune functions simultaneously.

It also seems plausible that a strategic response in birds could occur with the immune system, analogous to strategic energy budgeting, whereby certain components of the immune response are downregulated during costly periods of the annual cycle (winter), while others are maintained because of their necessity. For example, during critical periods, it is hypothesized that there should be a shift toward specific immunity and away from costly components of the immune response (Lee 2006), and winter might be considered such a critical period.

In this study, one of our goals was to determine the response of the immune system in black-capped chickadees (Poecile atricapilus) to unpredictable food availability. We therefore examined black-capped chickadees during wintertime, when unpredictable resources are a significant component of daily life. We tested how experimental chickadees would respond in energy budgeting and immune functions in response to unpredictable food availability in comparison to those fed ad lib. We predicted that if individuals faced with unpredictable food lost body mass, then many/most immune functions would decline, as shown for birds exposed to persistent energy imbalance. Alternatively, if chickadees increased in fat and body mass as a hedge against energy imbalance - as shown for some birds exposed to unpredictable food - then we predicted that many/most immune components would show no significant difference compared with controls fed ad lib. In this specific case, if there were declines in immune function, then we predicted that they might be for the most energetically costly immune components (e.g., fever response; Lee 2006). Whatever the responses, we also predicted that it would likely take several days for the experimental birds to adjust their energetic composition (body and fat mass) to compensate for unpredictable food.

\section{Methods}

\section{Bird Collection}

Black-capped chickadees were captured near Rimouski, Quebec, Canada, during January and February 2015; therefore, all birds were considered to be after-hatch year (born after May 2014) or older. Birds were collected via mist nets (Avinet, Dryden, NY) or potter traps in the Forêt d'Enseignement et de Recherche Macpès (48.298, -65.547). All captured birds were placed individually into cloth bags and transported back to the avian facility of the Université du Québec à Rimouski (UQAR). Once in the animal room, each bird was fitted with a unique color band and weighed $( \pm 0.01 \mathrm{~g})$, and the wing chord and tarsus lengths were measured $( \pm 1 \mathrm{~mm})$. Birds were housed individually for the course of the experiment $(41.3 \times 41.9 \times 32.4-\mathrm{cm}$ cages $)$. The room was kept at a constant $-15^{\circ} \pm 2^{\circ} \mathrm{C}$ on a $10 \mathrm{~L}: 12 \mathrm{D}$ cycle. Procedures were approved by the UQAR Animal Care Committee (CPA60-15-158).

\section{Feeding Treatments}

A total of 27 black-capped chickadees were brought into captivity, acclimatized for at least $5 \mathrm{~d}$, and provided water ad lib. and the following amounts of food daily: $13 \pm 0.3$ g shucked black-oil sunflower seeds, $1.5 \pm 0.02 \mathrm{~g}$ (wet mass) frozen crickets, and $0.41 \pm 0.01 \mathrm{~g}$ live mealworms. These amounts were more than what was consumed on a daily basis (i.e., food was provided ad lib.). During $4 \mathrm{~d}$ of the acclimatization period, all orts (unconsumed food) were collected and dried in a drying oven at $75^{\circ} \mathrm{C}$ for $48 \mathrm{~h}$. Fresh food samples were also dried, and daily dry mass intake was calculated as the difference between dry mass of food offered minus dry mass orts. Following acclimatization, birds were randomly assigned to two groups, controls and experimentals (13 birds in the control group [two female, 10 male, and one unknown] and 14 birds in the experimental group [four female and 10 male]; see "Molecular Sex Determination"). Controls always received food ad lib. (approximately four times daily food intake), and they consumed a total of $5.1 \pm 0.2 \mathrm{~g}$ wet mass/day (table 1). Experimental birds were provided with reduced food (65\% of their respective ad lib. consumption by mass, $63 \%$ by estimated metabolizable energy; table 1) on some days and food ad lib. all other days. A random number generator was used to determine the particular days of reduced feeding (the same $10 \mathrm{~d}$ for all experimental birds) for the entire course of the study ( 25 total days in the experiment). 


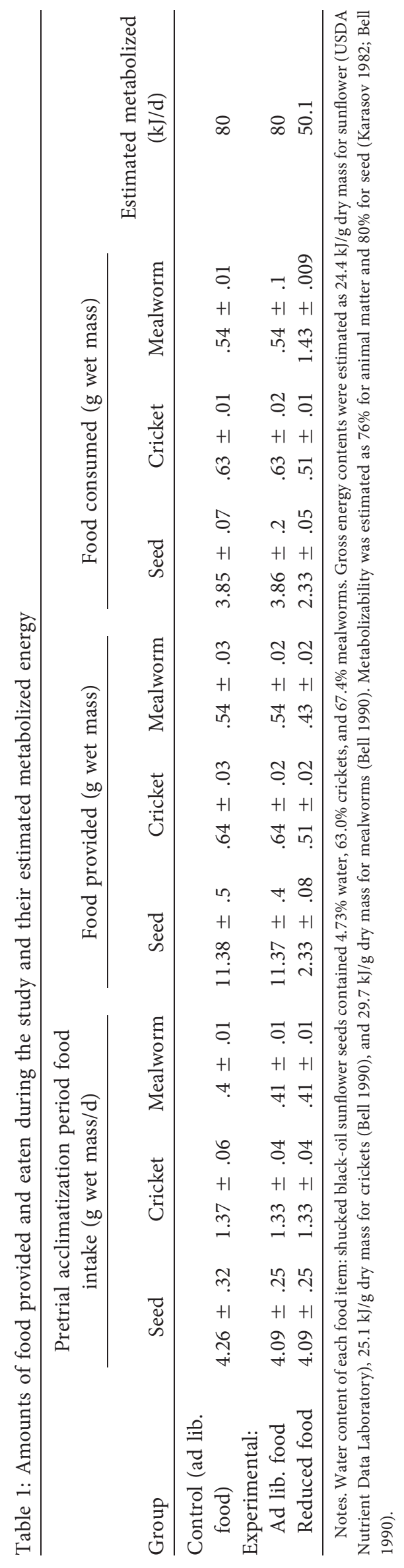


Reduced days were always followed by a day of feeding ad lib. (i.e., no consecutive reduced days) because of animal welfare concerns (see fig. 1A). Finally, food intake was measured in both groups six times during the course of the study. For experimental birds, this was done on $3 \mathrm{~d}$ on which provided food was reduced and $3 \mathrm{~d}$ on which it was ad lib.

\section{Molecular Sex Determination}

Polymerase chain reaction (PCR) techniques were completed to determine genetic sexes. All samples were submitted to the University of Wisconsin-Madison Biotechnology Gene Expression Center, and methods were adapted from the protocol developed by Griffiths et al. (1998). This protocol utilizes the P2/ P8 primers which identify congenital heart defect genes associated with either $\mathrm{ZZ}$ in males or $\mathrm{ZW}$ in females; therefore, one band ( $350 \mathrm{bp}$ ) is amplified in males and two (350 bp and $450 \mathrm{bp}$ ) in females (Griffiths et al. 1998; Ramsay et al. 2003). Each set of PCR reactions was run in duplicate with a positive male control.

\section{Sampling Protocol}

On day 5 (fig. $1 B$ ) a constitutive blood sample (used to measure complement lysis) was drawn from all birds, using a 27-gauge needle from the brachial vein and collected in a 70-100 $\mu \mathrm{L}$ capillary tube with heparin as an anticoagulant. Blood samples never exceeded $1 \%$ of the birds' total body mass. Drops of whole blood were smeared on microscope slides and stained for routine survey of basic white blood cell counts and various leukocyte ratios (Demas et al. 2011; Owen 2011).
On day 8 , birds were subjected to a PHA swelling assay to assess delayed-type hypersensitivity. This was completed following the methods outlined by Smits et al. (1999). Briefly, all birds were injected with $26 \mu \mathrm{L}$ of a $1-\mathrm{mg} / \mathrm{mL}$ PHA-phosphate buffered saline (PBS) solution (Sigma, L 9017) in the left wing web. At the same time, birds were also injected with $26 \mu \mathrm{L}$ of sterile PBS solution in their right wing web. The left and right wing webs were measured five times before injection and five times $24 \pm 0.5 \mathrm{~h}$ after injection, using a gauge micrometer (Noreen et al. 2011). Correcting post-PHA injection wing thickness values with post-PBS injection wing thickness values (two-wing technique) versus correcting with preinjection wing thickness values (one-wing technique; Smits et al. 1999) did not yield different results; we report values using the one-wing technique.

On day 12, a constitutive blood sample was taken (for complement lysis), after which birds were injected intramuscularly with $50 \mu \mathrm{L}$ of a 1:1 solution of keyhole limpet hemocyanin (KLH; Calbiochem, Darmstadt, Germany) and complete Freud's adjuvant solution (Sigma-Aldrich; Killpack et al. 2015). Seven days later, a second blood sample was taken to measure primary antibody response.

In order to measure the fever response, on day 24 at around 4 p.m., chickadees in both groups were injected intramuscularly with $24 \mu \mathrm{L}$ of lipopolysaccharides (LPS) diluted in sterile PBS (Millet et al. 2007; Killpack et al. 2015) at a concentration of $1.0 \mathrm{mg} / \mathrm{g}$ body weight to induce an acute phase response and subsequently measure production of haptoglobin, an acute phase protein. The next morning $(16 \pm 0.4 \mathrm{~h}$ after LPS injection; around 8:00 a.m.), a blood sample was taken from the brachial

A

\begin{tabular}{|c|c|c|c|c|c|c|c|c|c|c|c|c|c|c|c|c|c|c|c|c|c|c|c|c|c|}
\hline Day & 1 & 2 & 3 & 4 & 5 & 6 & 7 & 8 & 9 & 10 & 11 & 12 & 13 & 14 & 15 & 16 & 17 & 18 & 19 & 20 & 21 & 22 & 23 & 24 & 25 \\
\hline Experimental & & & & & & & & & & & & & & & & & & & & & & & & & \\
\hline Control & & & & & & & & & & & & & & & & & & & & & & & & & \\
\hline
\end{tabular}

$\mathrm{B}$

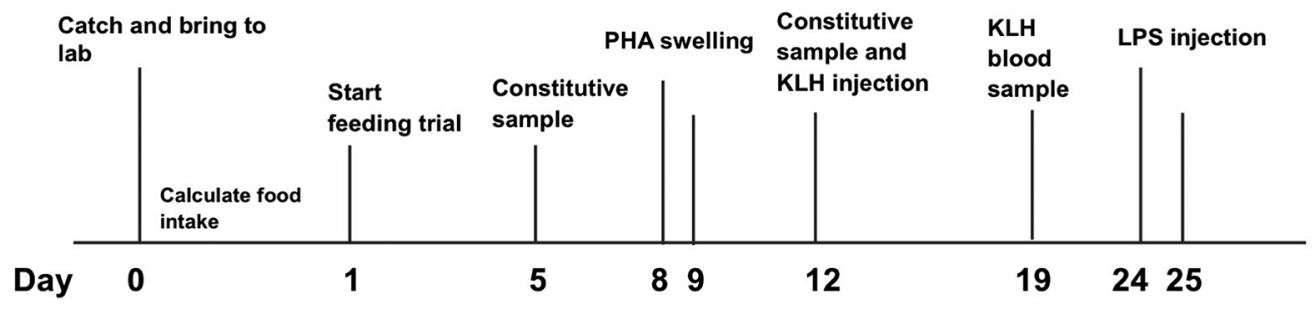

Figure 1. A, Feeding schedule for experimental and control birds. Experimental birds received a reduced amount of food on selected days of the study (open boxes; for details, see "Methods"). All other days of the study, experimental birds received food ad lib. (filled boxes). Control birds received food ad lib. on every day of the study. B, Sampling timeline. Food treatment study began on day 1 , after birds were acclimated and food intake had been calculated for at least $4 \mathrm{~d}$. Vertical lines represent when a component of the immune system was measured. All samplings were done on both control and treatment birds. KLH, keyhole limpet hemocyanin; LPS, lipopolysaccharides; PHA, phytohemagglutinin. 
vein. Pre- and postinjection (16 h after LPS injection) cloacal temperatures were measured $\left( \pm 0.05^{\circ} \mathrm{C}\right.$; Physitemp, Clifton, NJ) to assess the fever response. All blood samples were separated and then stored at $-20^{\circ} \mathrm{C}$ until analysis could be completed.

\section{Measures of Body Composition}

Throughout the study, total fat and lean mass were measured using a quantitative magnetic resonance (QMR) EchoMRI machine (EchoMRI, Houston; Guglielmo et al. 2011; $\pm 0.01 \mathrm{~g}$ ). The QMR measurements were taken three times, and the average was recorded on days 5, 15, and 22. Morning body mass (around 7:30 a.m.) was taken every other day on each bird throughout the course of the study. Body mass was measured before each blood sample or injection $( \pm 0.01 \mathrm{~g})$.

\section{Immune Assays}

Complement Lysis. Constitutive blood samples were analyzed for complement-mediated lysis ability. To measure complement lysis ability, we used an in vitro assay that employs spectrophotometry to detect complement lysis activity. We followed methods previously outlined by Killpack et al. (2015; see Matson et al. 2005; Merchant et al. 2006). Each plate obtained samples from both groups and also multiple positive and negative controls. Briefly, $20 \mu \mathrm{L}$ of chickadee plasma were diluted into $60 \mu \mathrm{L}$ of PBS. Then $80 \mu \mathrm{L}$ of a $2 \%$ rabbit red blood cell (RRBC) solution was added to each sample dilution. Positive control samples were created by adding $20 \mu \mathrm{L}$ of heat-inactivated plasma diluted in $60 \mu \mathrm{L}$ of PBS to $80 \mu \mathrm{L}$ of a $1 \%$ Triton-X-100/2\% RRBC solution. Negative control samples consisted of a 1:1 PBS and RRBC solution. Plasma blanks were created by adding $20 \mu \mathrm{L}$ of heat-inactivated plasma diluted in $60 \mu \mathrm{L}$ of PBS to $80 \mu \mathrm{L}$ of the $2 \%$ RRBC solution. All samples (and controls) were then incubated in a water bath set at $56^{\circ} \mathrm{C}$ for $30 \mathrm{~min}$. After incubation, samples were centrifuged for $2 \mathrm{~min}$ at 2,000 $\mathrm{g}$ to form a pellet of unlysed red blood cells. Forty microliters from each tube was then loaded (in triplicate) onto a 96-well plate. The plate was then read at $540 \mathrm{~nm}$, and values are reported as percent lysed [(optical density of sample - optical density of negative control)/ (optical density of positive control)].

Enzyme-Linked Immunosorbent Assay (ELISA) for IgY Antibodies. Blood collected $7 \mathrm{~d}$ after the KLH injection was used to measure primary antibody production for KLH-specific IgY antibodies. Preinjection antibody levels and primary antibody production were measured using an indirect ELISA and following methods outlined by Killpack et al. (2015). On each plate, all samples, a PBS negative control, black-capped chickadee negative control, and black-capped chickadee strong-positive control (from a previous validation trial) were plated in triplicate. A flatbottom, high-binding 96-well plate (Nunc, 442404) was coated with $50 \mu \mathrm{L} /$ well antigen $(0.5 \mathrm{mg} / \mathrm{mL} \mathrm{KLH}$ in coating buffer [0.015 $\left.\mathrm{M} \mathrm{Na}_{2} \mathrm{CO}_{3}, 0.035 \mathrm{M} \mathrm{NaHCO}_{3}, \mathrm{pH} 9.6\right]$ ) and then incubated at $4^{\circ} \mathrm{C}$ overnight. The plate was then washed with wash buffer (PBS with $0.05 \%$ Tween) using a Biotek ELx 405 microplate washer and blocked with $100 \mu \mathrm{L}$ blocking buffer (5\% nonfat dry milk with $0.5 \%$ Tween) for $1 \mathrm{~h}$ at $37^{\circ} \mathrm{C}$. The blocking buffer was then discarded, and $100 \mu \mathrm{L}$ of sample serum (diluted 1:100 in blocking buffer) was added to each well for a 1-h-long incubation at $37^{\circ} \mathrm{C}$. After incubation, the plates were washed with wash buffer, and $50 \mu \mathrm{L}$ of horseradish peroxidase-conjugated goat-anti-wild bird IgG (Bethyl Laboratories, A140-110P) diluted 1:700 in wash buffer was added to each well and incubated for $1 \mathrm{~h}$ at $37^{\circ} \mathrm{C}$. Plates were washed with wash buffer, and $100 \mu \mathrm{L}$ of ABTS solution was added and incubated for $10 \mathrm{~min}$ in the dark at room temperature. After incubation, $100 \mu \mathrm{L}$ of $1 \%$ stop develop solution was added to stop the reaction. The optical densities of the wells were read at $405 \mathrm{~nm}$, and absorbance values of the triplicate wells were averaged. Average absorbance values for the postpriming sample were then corrected for background absorbance by subtracting the average absorbance value for the preinjection sample from the same bird.

Haptoglobin (Acute Phase Protein) Assay. Blood samples taken after the LPS injection were used to measure the acute phase response by analyzing haptoglobin (an acute phase protein) levels. To measure haptoglobin, we used an in vitro spectrophotometric assay (Killpack et al. 2015). Haptoglobin was quantified $(\mathrm{mg} / \mathrm{mL})$ by using the protocol provided with a commercially available kit (TP801; Tri-DD, Boonton Twp, NJ), with one modification. Because of the hemolysis in some samples, we read all samples at an absorbance of $540 \mathrm{~nm}$ after the addition of reagent 1 (stabilized hemoglobin). Then regent 2 (chromogen) was added, the plate was incubated for $5 \mathrm{~min}$ at room temperature, and the final reading was at an absorbance of $630 \mathrm{~nm}$. Haptoglobin concentrations were determined using a standard curve, which was based on absorbance at $630 \mathrm{~nm}$ obtained from the five different haptoglobin concentration standards provided by the kit. In a subsequent analysis, we controlled for any hemolysis in samples - and thus an effect of that on the calculated plasma haptoglobin levels - by including absorbance values at $540 \mathrm{~nm}$ as a covariate in an analysis of covariance (see "Statistical Analyses"). Both the raw haptoglobin concentration values are reported as well as the adjusted least squares means values (adjusted for any small differences related to absorbance at $540 \mathrm{~nm}$ ).

\section{Statistical Analyses}

To examine whether total body mass, fat/lean body mass, and complement lysis ability changed over time with respect to experimental group, we ran three separate repeated-measures ANOVA models with group, sex, and date as categorical predictors and the interaction between group $\times$ date in the model. When interaction effects or sex was not found to influence the dependent variables, we removed them from the final models. In no case was a main predictor (related to a specific hypothesis) removed. In these and other ANOVAs, we present the $F$ statistic with the corresponding degrees of freedom as subscripts.

The temperature and body mass response to LPS is reported as a change in temperature and body mass, respectively, before and after injection. Wing swelling is expressed as a change in 
swelling (wing thickness after injection - wing thickness before injection). We conducted two-way ANOVAs to test for the effects of the treatment on these and other immune responses. Initially, we measured the effects of treatment on the fever response (temperature response and mass lost after injection), primary antibody response (KLH injection), and delayed-type hypersensitivity response (PHA wing swelling) with group and sex as categorical predictors. Further, we conducted an ANCOVA to test for the effect of treatment on haptoglobin levels (another aspect of the fever response) with group and sex as categorical predictors and absorbance values at $540 \mathrm{~nm}$ as a continuous predictor. For both the two-way ANOVAs and the ANCOVA, when sex was not found to influence the dependent variables, we grouped all sexes for the final analysis. Additionally, we used simple linear regression to determine whether change in fat mass (last day - first day) was predictive for either the haptoglobin response or the primary antibody response $(\mathrm{KLH})$ as well as ANCOVA with change in fat mass as the covariate. In the case of wing swelling, we also conducted two post hoc, two-way ANOVAs to determine whether there were differences among groups between the swelling response due to PHA injection and the swelling response due to PBS injection alone. Last, we conducted a two-way ANOVA to test for the difference between food intake in the two groups during the course of the experiment, using group, type of feeding day (reduced vs. ad lib. in the experimentals), and date as categorical predictors. Where applicable, we conducted Tukey's post hoc analyses to make specific pairwise comparisons following ANOVAs. We consider a trend to be reflected by $0.05 \leq P \leq 0.1$, and $P \leq 0.05$ reflects a significant difference. Data were analyzed using STATISTICA (ver. 12; StatSoft 2003). All data presented are means \pm SEM, unless otherwise stated.

\section{Results}

During the course of the study, three birds died, two of which were controls (one male, one female) and one experimental (male).

\section{Responses in Energy Budgeting}

Body mass of chickadees changed significantly over time $\left(F_{11,220}=\right.$ 18.64, $P<0.001)$, and experimental birds maintained significantly higher mass over time compared with control birds $\left(F_{1,20}=4.37\right.$, $P=0.05$; fig. 2). Additionally, $\operatorname{sex}\left(F_{1,20}=4.35, P=0.05\right)$ and the group $\times$ date interaction $\left(F_{11,220}=5.43, P<0.001\right)$ were found to be significant predictors of body mass variation. After excluding days 1-7 because it appeared to take about $7 \mathrm{~d}$ for the treatment to take effect, experimental birds maintained significantly more body mass over time $(12.79 \pm 0.09 \mathrm{~g})$ compared with control birds $\left(11.83 \pm 0.07 \mathrm{~g} ; F_{1,20}=7.3, P=0.014\right)$. Experimental birds maintained significantly higher fat mass over the course of the study $\left(1.28 \pm 0.08 \mathrm{~g} ; F_{1,22}=32.64, P<\right.$ 0.001 ; fig. 3$)$ compared with controls $(0.44 \pm 0.05 \mathrm{~g})$, and this increased after day $5\left(F_{2,44}=8.37, P=0.001\right)$. Lean mass was similar between the two groups $\left(F_{1,22}=0.06, P=0.81\right)$ but did

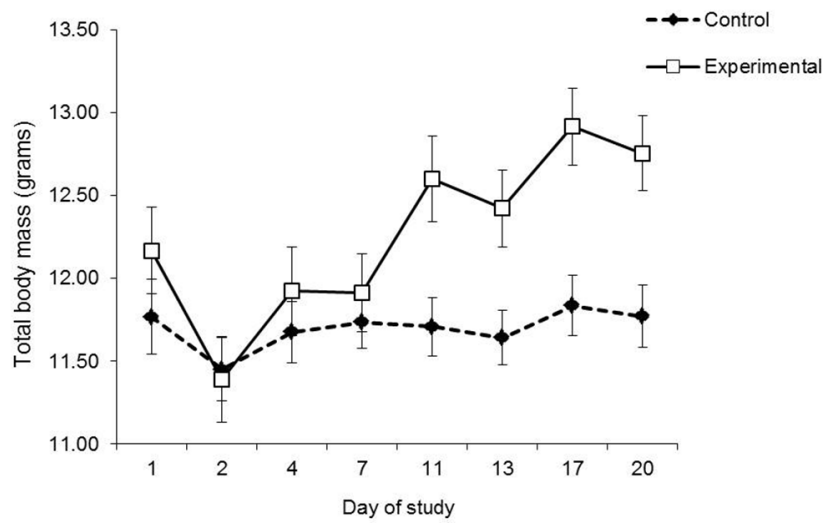

Figure 2. Total body mass over the course of the study for control and experimental birds. After $7 \mathrm{~d}$ of the study, treatment birds maintained significantly higher body mass compared with control birds (see "Results"). Error bars represent standard errors.

vary according to date $\left(F_{2,44}=102.01, P<0.001\right)$, with birds having higher lean masses later in the study (after day 5; data not shown).

There was also a difference between groups with regard to their total consumed metabolizable energy during the course of the experiment $\left(F_{1,149}=32.1, P<0.001\right)$ and the type of day the food was consumed (i.e., reduced vs. ad lib. for the experimentals; $F_{1,140}=44.77, P<0.001$; table 1; fig. 4). Post hoc Student's $t$-tests revealed that this significant difference was driven by a difference in consumption on reduced days $(P<0.001)$ but not ad lib. days $(P=0.773)$. For group means for each immune and body composition measure and complete statistical results, see table 2.

\section{Responses in Immune Function}

Complement lysis ability did not differ significantly between groups $\left(F_{1,22}=0.41, P=0.53\right)$ but declined with date $\left(F_{1,22}=5.7\right.$, $P=0.026$; fig. 5A). After vaccination with LPS, experimental birds had significantly lower values of haptoglobin concentration compared with controls (raw values; control: $0.53 \pm 0.02 \mathrm{mg}$ / $\mathrm{mL}$; experimental: $\left.0.41 \pm 0.02 \mathrm{mg} / \mathrm{mL} ; F_{1,21}=7.83, P<0.012\right)$ and lost more mass $\left(-0.596 \pm 0.1 \mathrm{~g} ; F_{1,22}=17.92, P<0.001\right)$ compared with control birds $(-0.084 \pm 0.054 \mathrm{~g}$; fig. $5 B, 5 C)$. Haptoglobin levels were also significantly, positively related to the absorbance values at $540 \mathrm{~nm}\left(F_{1,21}=12.45, P<0.002\right)$; however, when controlling for the effect of extra absorbance, which was possibly due to some hemolysis, the control and experimental groups were still significantly different, with experimentals having lower haptoglobin levels (ANCOVA adjusted least squares means; control: $0.52 \pm 0.02 \mathrm{mg} / \mathrm{mL}$; experimental: $0.42 \pm$ $\left.0.02 \mathrm{mg} / \mathrm{mL} ; F_{1,21}=7.8, P=0.011\right)$. Interestingly, haptoglobin response (raw) was significantly inversely related to delta fat mass by simple linear regression $(P=0.007$; fig. 6$)$, although by ANCOVA neither delta fat mass nor group were significant in ANCOVA $(P>0.5, P=0.18$, and $P=0.17$, respectively, for interaction of delta fat mass and group). Experimental birds also 


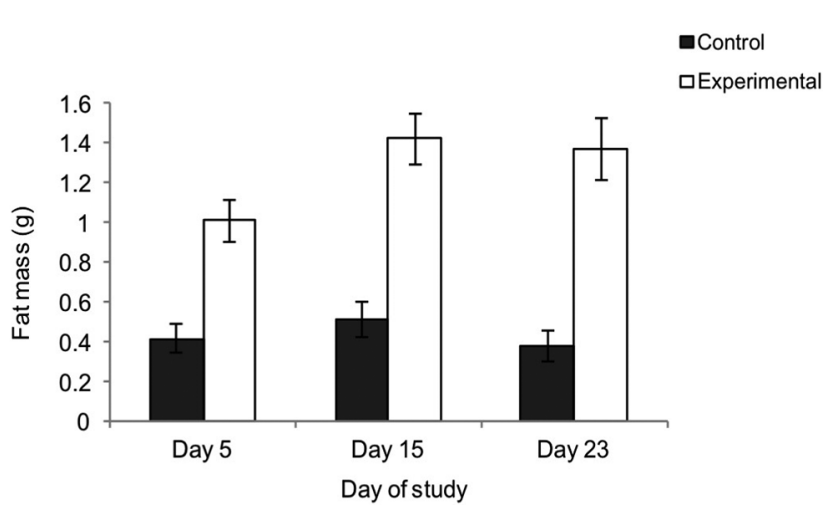

Figure 3. Fat mass on $3 \mathrm{~d}$ of the study for control and treatment birds. Experimental birds had significantly higher levels of fat mass, as measured by use of a quantitative magnetic resonance machine. Error bars represent standard errors.

responded to injection of LPS by significantly decreasing their body temperature $\left(F_{1,22}=7.06, P=0.01 ;-0.92^{\circ} \pm 0.35^{\circ} \mathrm{C}\right.$; fig. $5 D$ ), whereas control birds had no significant change after injection $\left(0.34^{\circ} \pm 0.30^{\circ} \mathrm{C}\right)$.

Preinjection antibody levels and primary antibody response (KLH injection) did not vary significantly between groups $\left(F_{1,44}=\right.$ $0.29, P=0.59$; fig. $5 B$ ). There was also no significant difference between samples (preinjection vs. primary antibody response), indicating that birds did not increase their antibody response after injection with $\mathrm{KLH}\left(F_{1,44}=0.41, P=0.53\right)$. Antibody responses did not vary with delta fat mass (data not shown).

After vaccination with PHA, there was no significant difference in wing swelling between experimental groups $\left(F_{1,23}=1.13\right.$, $P=0.3$; fig. $5 F$ ). However, when we analyzed groups independently to examine whether there was significantly more swelling due to PHA than PBS alone, we found that control birds showed a trend toward a response to the PHA injection with more swelling $\left(F_{1,24}=3.88, P=0.06\right)$ compared with the PBS alone but that experimental birds did not show a trend toward swelling $\left(F_{1,25}=0.05, P=0.83\right)$.

\section{Discussion}

\section{Overview}

The black-capped chickadees in this study were provided daily either food ad lib. (control) or a reduced amount of food on random days (experimental). The experimental group maintained higher body and fat mass during the study compared with controls. While this result took about $7 \mathrm{~d}$ to occur, it supports the adaptive fattening response hypothesis proposed by Witter et al. (1995), in which animals faced with periodic food deprivation strategically increase fat reserves in order to buffer themselves against the uncertainty of receiving adequate amounts of food the following day. Given this arguably strategic energy budgeting, we did not expect to see differences in chickadee immune function compared with controls, except for possible reductions in the most expensive immune functions (Lee 2006). We discuss in more detail the strategic energy budgeting of the chickadees and the varied responses of immune features that we measured.

\section{Energy Budgeting in Relation to Unpredictable Food}

Although some studies in birds experimentally challenged with unpredictable food found that birds lost mass (Acquarone et al. 2002; Cucco et al. 2002), strategic fattening seems to be the rulenot the exception - in small passerines challenged with unpredictable food availability (Bednekoff and Krebs 1995; Cuthill et al. 2000). Our experimental chickadees never showed lower body masses than the controls, though it took about a week of the treatment - which included $3 \mathrm{~d}$ of reduced food-before their body masses were significantly higher than in controls. The increased body mass was achieved entirely by increases in body fat, with no significant change in lean body mass.

It is interesting to consider the mechanism by which experimental birds gained excess total body and fat mass. During the course of the experiment, we measured food intake over $6 \mathrm{~d}$ (three reduced and three ad lib. days). Control birds consumed about $80 \mathrm{~kJ} / \mathrm{d}$ metabolizable energy (fig. 5; table 1). This is similar to that measured in chickadees housed in outdoor aviaries at winter temperatures (Howitz 1981) and higher than the energy expended by free-living chickadees in wintertime, measured with doubly labeled water ( $66 \mathrm{~kJ} / \mathrm{d}$; Karasov et al. 1992). Experimental birds were consuming similar amounts of food on ad lib. days compared with control birds. Hence, their increase in total body and fat mass must have been due to another mechanism, such as decreased metabolic rate, which other measurements indicated (E. A. Cornelius, unpublished data), perhaps achieved by reducing body temperature (Chaplin 1976; Lewden et al. 2014) or decreased activity (Dall and Witter 1998). It is intriguing that both our experimental chickadees and free-living chickadees in wintertime appear to exhibit lower metabolism than captive chickadees fed ad lib. held either outdoors (Howitz 1981) or indoors at low temperature (this study). That suggests that both free-living chickadees and our experimental chickadees

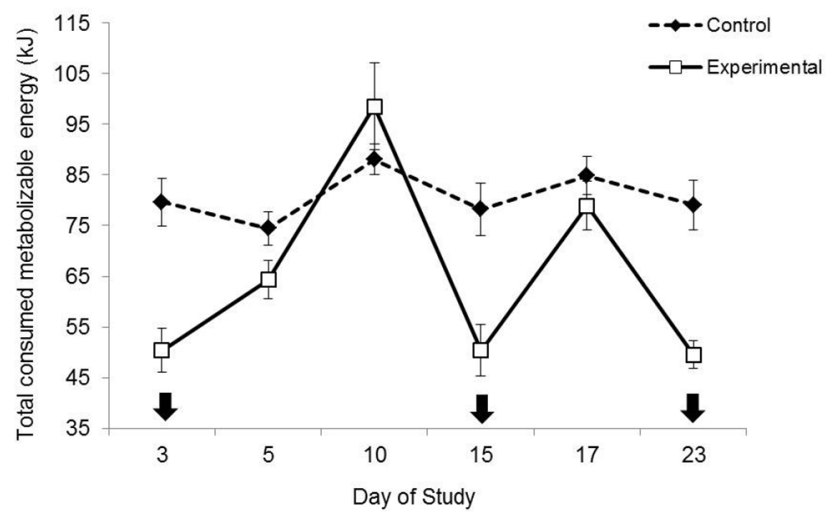

Figure 4. Estimated metabolizable energy consumed during the course of the experiment. Data represent a full 24-h period. Arrows indicate the reduced days on which significantly lower food intake was measured. Experimental birds consumed similar amounts of energy compared with control birds on ad lib. days. 
Table 2: Immune and physiological measures and summary of results of ANOVA or ANCOVA for the effect of treatment on immune function and physiology of black-capped chickadees

\begin{tabular}{|c|c|c|c|c|c|c|}
\hline Measure and day of study & Control & Experimental & Factor & $F$ & df & $P$ \\
\hline \multicolumn{7}{|l|}{ Body mass (g): } \\
\hline 1 & $11.77 \pm .22^{\mathrm{A}}$ & $12.16 \pm .26^{\mathrm{A}}$ & Group & 4.37 & 1,20 & $<.05^{\star}$ \\
\hline 7 & $11.73 \pm .16^{\mathrm{A}}$ & $11.91 \pm .23^{\mathrm{A}}$ & Sex & 4.35 & 1,20 & $<.05^{*}$ \\
\hline 13 & $11.64 \pm .17^{\mathrm{A}}$ & $12.42 \pm .23^{\mathrm{B}}$ & Day & 18.64 & 11,220 & $<.001^{*}$ \\
\hline 20 & $11.77 \pm .19^{\mathrm{A}}$ & $12.75 \pm .23^{\mathrm{B}}$ & Group $\times$ day & 5.43 & 11,220 & $<.001^{*}$ \\
\hline \multicolumn{7}{|l|}{ Fat mass $(\mathrm{g})$ : } \\
\hline 5 & $.418 \pm .07$ & $1.00 \pm .11$ & Group & 32.64 & 1,22 & $<.001^{*}$ \\
\hline 15 & $.516 \pm .09$ & $1.42 \pm .12$ & Day & 8.37 & 2,44 & $.001^{*}$ \\
\hline 23 & $.379 \pm .08$ & $1.37 \pm .15$ & & & & \\
\hline \multicolumn{7}{|l|}{ Lean mass $(\mathrm{g})$ : } \\
\hline 5 & $8.62 \pm .16$ & $8.81 \pm .24$ & Group & .06 & 1,22 & .81 \\
\hline 15 & $9.5 \pm .11$ & $9.52 \pm .19$ & Day & 102.0 & 2,44 & $<.001$ \\
\hline 23 & $9.53 \pm .14$ & $9.69 \pm .2$ & & & & \\
\hline \multicolumn{7}{|l|}{ Complement ability (OD): } \\
\hline 5 & $.105 \pm .02$ & $.103 \pm .02$ & Group & .41 & 1,22 & .53 \\
\hline 12 & $.031 \pm .01$ & $.074 \pm .02$ & Day & 5.7 & 1,22 & $.026^{*}$ \\
\hline \multirow[t]{2}{*}{ Haptoglobin $(\mathrm{mg} / \mathrm{mL})$} & $.521 \pm .02$ & $.397 \pm .03$ & Group & 7.83 & 1,21 & $.011^{\star}$ \\
\hline & & & Absorbance $540 \mathrm{~nm}$ & 12.45 & 1,21 & $.002^{\star}$ \\
\hline \multicolumn{7}{|l|}{ KLH (OD): } \\
\hline Before injection & $.272 \pm .01$ & $.273 \pm .01$ & Group & .29 & 1,44 & .59 \\
\hline \multirow[t]{2}{*}{ Primary response } & $.287 \pm .02$ & $.289 \pm .02$ & Sex & 1.46 & 2,44 & .24 \\
\hline & & & Sample & .41 & 1,44 & .53 \\
\hline PHA (mm) & $.01 \pm .01$ & $-.0006 \pm .01$ & Group & 1.13 & 1,23 & .3 \\
\hline
\end{tabular}

Note. Results are provided from the initial repeated-measures ANOVA, where days 1-7 are included. Immune and physiological values are means \pm SEM. Values for a given physiological measure that do not share the same letter are significantly different, as determined by Tukey's post hoc tests. KLH, keyhole limpet hemocyanin; OD, optical density; PHA, phytohemagglutinin.

*Significance at $\alpha=0.05$.

may often behave in a similar strategic energy-conserving fashion (Chaplin 1976; Lewden et al. 2014). Future studies should examine these ideas as well as the mechanisms involved.

\section{Immune Function in Relation to Unpredictable Resources}

Given the black-capped chickadee's strategic energy budgeting (i.e., anticipatory storage of fat), we did not expect to see differences in immune function of experimental birds compared with controls, except for possible reductions in the most expensive immune functions (Lee 2006). In many regards, this prediction was confirmed, as we look across the five assays of immune function that we used.

Complement lysis ability measures a constitutive ability to lyse membranes of foreign cells. This ability along with constitutive levels of IgY antibodies are both considered to be relatively lowcost immune features (Lee 2006). Indeed, even in birds exposed to continuous food restriction, these both may not be reduced compared with controls fed ad lib. (see Killpack et al. 2015 and references therein). However, one study did find that fasted refed mallards (Anas plathyrhynchos) had decreased plasma IgY and natural antibodies (Bourgault et al. 2009). Perhaps not surprisingly then, we found no significant differences in either of these immune features in experimental chickadees exposed to periodic food restriction compared with controls fed ad lib. However, both groups decreased their complement lysis activity between days 5 and 12 of the study, which might reflect an effect of handling manipulation, captivity, or progression of season. It is also possible that these components of the immune system were measured too soon after imposing the food restriction and that it actually takes longer for this type of manipulation to cause an impact (Hegemann et al. 2013; Fowler and Williams 2015).

The stimulated primary antibody response to KLH vaccination and the cell-mediated responses that are components of the PHA swelling test are considered to have low to medium use costs (Lee 2006). Neither of these assays in chickadees showed significant differences between experimentals and controls. Counter to our results, previous studies have found a significant reduction in delayed-type hypersensitivity response in food-restricted birds. For example, food-restricted sand martins (Riparia riparia) exhibited a significantly decreased swelling response compared with birds fed ad lib. (Brzęk and Konarzewski 2007), and fasted and sub-ad lib. fed yellow-legged gulls (Larus cachinnans) were found to have a decreased cell-mediated response (PHA injection) compared with control birds fed ad lib. (Alonso-Alvarez and Tella 2001; see also Love et al. 2008). However, in these studies, food-restricted birds had decreased mass compared with controls, which suggests that perhaps birds in a decreased con- 

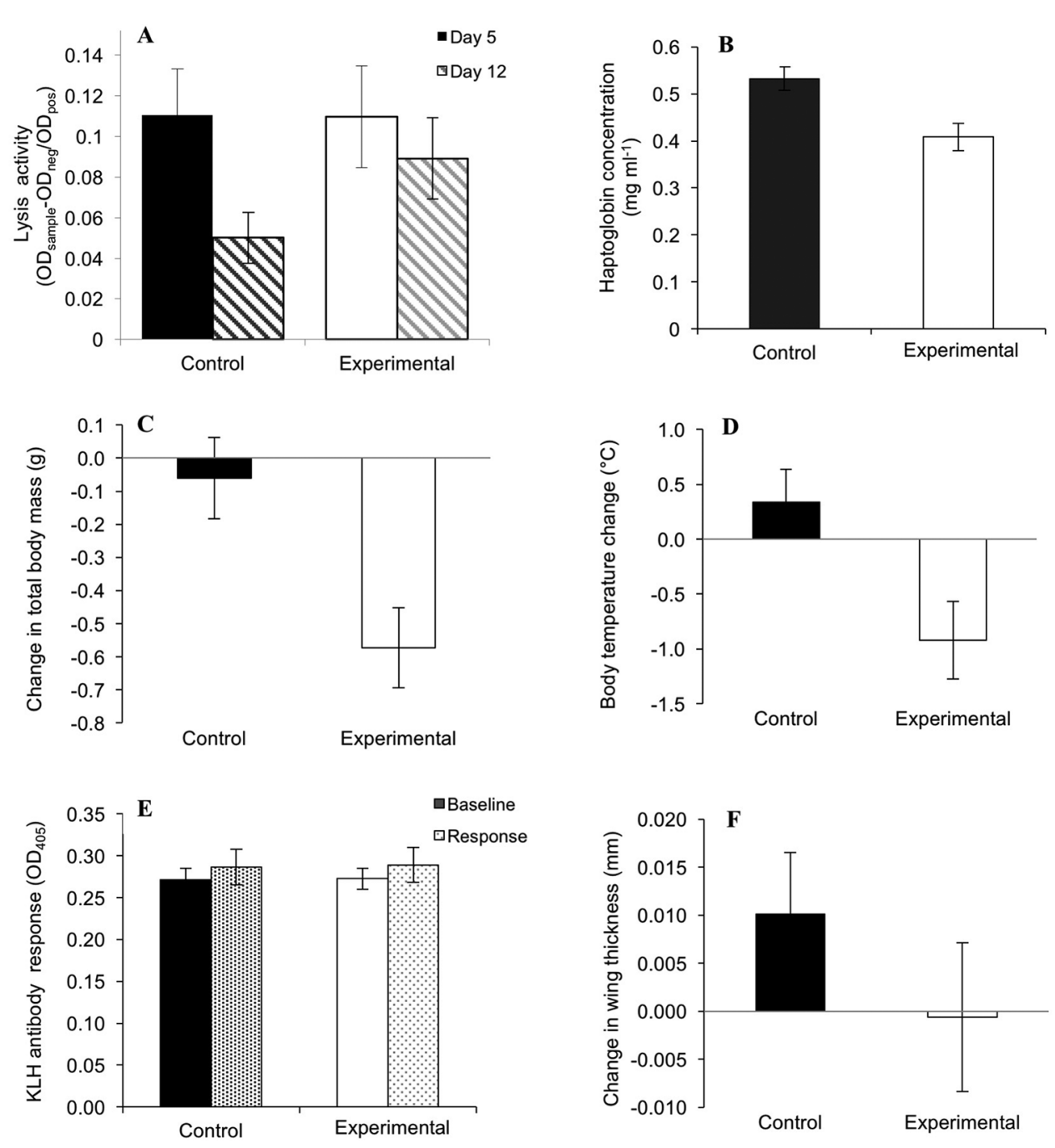

Figure 5. Immune measures of complement lysis $(A)$, haptoglobin concentration after lipopolysaccharides (LPS) injection (B), body temperature response to LPS $(C)$, body mass response to LPS $(D)$, preinjection and primary antibody response to keyhole limpet hemocyanin $(\mathrm{KLH} ; E)$, and wing swelling response $(F) . C, D$, and $F$ are represented as delta values (i.e., change in response). Complement lysis ability decreased significantly in control birds between days 5 and 12. Body temperature and mass declined in treatment birds after injection. Haptoglobin levels were lower in treatment birds compared with control birds. There was no significant treatment effect on complement lysis, primary antibody response, or wing swelling. Error bars represent standard errors. More detailed descriptions can be found in "Results."

dition have a decreased immune response, whereas in our study the experimentals had greater body mass than controls.

Energy costs are considered to be highest for local and systemic inflammatory responses that include increased production of proteins from the liver (Lee 2006; Owen-Ashley and Wingfield 2007), and it was these types of immune responses - concentration of haptoglobin - that differed significantly between experimental and control chickadees. Experimental birds exhibited lower acute phase protein haptoglobin level after LPS vaccination. Studies examining food restriction have also noted a decrease in haptoglobin concentration in food-restricted birds (Killpack et al. 2015). However, it is also important to note that one study examining energy budgets and immune function in skylarks (Alauda arvensis) over the course of an entire annual cycle did not find this same pattern; in fact, their research sug- gests that this acute phase response is such an important aspect of immune defense that it is constantly maintained (Hegemann et al. 2013). The inverse correlation of declining haptoglobin with increasing delta fat mass (fig. 5) seems consistent with the hypothesis that unpredictability of food supply triggers a tradeoff between fat gain and this component of the immune system. Besides reduced haptoglobin, experimental chickadees also had a significant reduction in body temperature after LPS challenge compared with control birds (similar to King and Swanson 2013). We also saw a significantly greater mass loss after LPS vaccination in experimental birds compared with control birds. It is possible that the mass loss we observed was due to infectioninduced anorexia (Langhans 2000) and that this anorexia was stronger in the experimental birds. Alternatively, is it possible that experimental birds had a higher fever compared with con- 


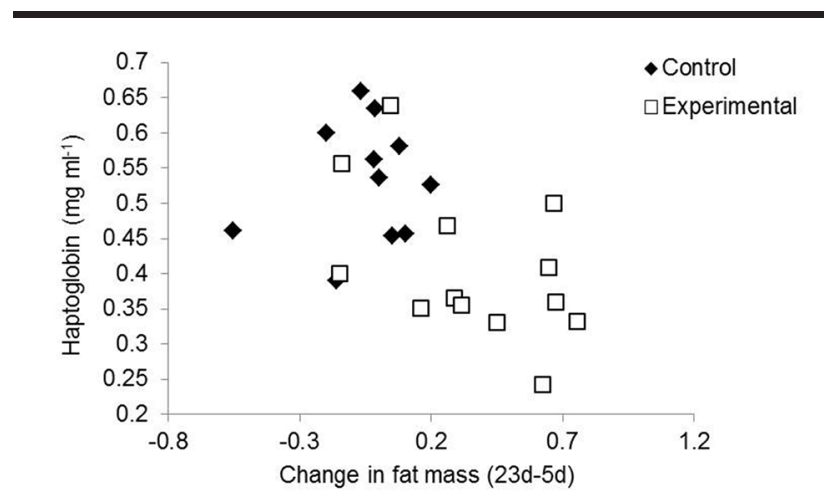

Figure 6. Haptoglobin response versus change in fat mass. Haptoglobin response (uncorrected) varied inversely with change in fat mass, defined as the difference in fat mass between experimental days 23 and 5 .

trols at a different time point than when it was measured and therefore burned more energy during the night, because it has previously been shown that the fever response to LPS differs depending on the time of day (Sköld-Chiriac et al. 2015). It also seems plausible that greater reduction in consumed energy by experimentals directly caused their greater mass loss, lower haptoglobin level, and greater reduction in body temperature.

\section{Summary}

In summary, experimental birds facing a cold environment and an unpredictable source of food gained significantly more total body and fat mass compared with birds given a food source ad lib., indicating that these birds are able to strategically buffer themselves against food uncertainty. During times of food unpredictability, especially costly components of chickadees' immune responses - such as fever response - may be lessened. However, less costly components of the immune response were not significantly influenced by food uncertainty, as was demonstrated by a lack of difference between groups for lysis ability, constitutive levels of IgY antibodies, primary antibody response, or delayed-type hypersensitivity. Future studies should aim to shed light on the mechanism behind the ability of food-restricted birds to gain extra fat mass and whether food restriction affects other components of immunity not measured here (especially secondary antibody responses).

\section{Acknowledgments}

We are grateful to Michal S. Wojciechowski for inviting us to present results from this article during the symposium "Phenotypic Flexibility of Energetics in a Seasonal World" of the Ninth International Congress of Comparative Physiology and Biochemistry in Krakow, Poland. We also thank Dr. Tess Killpack, Elena West, and Cherry Brown for protocols and laboratory support as well as Josianne Ruest for her help with bird maintenance. Financial support was provided by a Journal of Experimental Biology travel fellowship awarded to E.A.C. and a US Department of Agriculture-Hatch grant awarded to W.H.K. This work was also funded by Discovery grants from the Natural Sciences and Engineering Research Council of Canada to O.P.L. and F.V., a Canadian Foundation for Innovation (CFI) Leading Edge and Canada Research Chair funding to O.P.L., as well as a Leader Opportunity Fund award from the CFI to F.V.

\section{Literature Cited}

Acquarone C., M. Cucco, S.L. Cauli, and G. Malacarne. 2002. Effects of food abundance and predictability on body condition and health parameters: experimental tests with the hooded crow. Ibis 144:E155-E163.

Alonso-Alvarez C. and J.L. Tella. 2001. Effects of experimental food restriction and body-mass changes on the avian T-cellmediated immune response. Can J Zool 79:101-105.

Bednekoff P.A. and J.R. Krebs. 1995. Great tit fat reserves: effects of changing and unpredictable feeding day length. Funct Ecol 9:457-462.

Bell G.P. 1990. Birds and mammals on an insect diet: a primer on diet composition analysis in relation to ecological energetics. Stud Avian Biol 13:416-422.

Bourgault P., P. Perret, and M.M. Lambrechts. 2009. Food supplementation in distinct Corsican oak habitats and the timing of egg laying by blue tits. J Field Ornithol 80:127-134.

Brzęk P. and M. Konarzewski. 2007. Relationship between avian growth rate and immune response depends on food availability. J Exp Biol 210:2361-2367.

Buehler D.M., T. Piersma, K. Matson, and B.I. Tieleman. 2008. Seasonal redistribution of immune function in a migrant shorebird: annual-cycle effects override adjustments to thermal regime. American Naturalist 172:783-796.

Chaplin S.B. 1976. The physiology of hypothermia in the blackcapped chickadee, Parus atricapillus. J Comp Physiol 112:335344.

Cooper S.J. 2007. Daily and seasonal variation in body mass and visible fat in mountain chickadees and juniper titmice. Wilson J Ornithol 119:720-724.

Cucco M., R. Ottonelli, M. Raviola, and G. Malacarne. 2002. Variations of body mass and immune function in response to food unpredictability in magpies. Acta Oecol 23:271-276.

Cuthill I.C., S.A. Maddocks, C.V. Weall, and E.K.M. Jones. 2000. Body mass regulation in response to changes in feeding predictability and overnight energy expenditure. Behav Ecol 11:189-195.

Dall S.R. and M.S. Witter. 1998. Feeding interruptions, diurnal mass changes and daily routines of behaviour in the zebra finch. Anim Behav 55:715-725.

Demas G.E., D.A. Zysling, B.R. Beecher, M.P. Muehlenbein, and S.S. French. 2011. Beyond phytohemagglutinin: assessing vertebrate immune function across ecological contexts. J Anim Ecol 80:710-730.

Fowler M.A. and T.D. Williams. 2015. Individual variation in parental workload and breeding productivity in female European starlings: is the effort worth it? Ecol Evol 5:3585-3599.

Griffiths R., M.C. Double, K. Orr, and R.J. Dawson. 1998. A DNA test to sex most birds. Mol Ecol 7:1071-1075. 
Guglielmo C.G., L.P. McGuire, A.R. Gerson, and C.L. Seewagen. 2011. Simple, rapid, and non-invasive measurement of fat, lean, and total water masses of live birds using quantitative magnetic resonance. J Ornithol 152:75-85.

Hegemann A., K.D. Matson, H. Flinks, B.I Tieleman. 2013. Offspring pay sooner, parents pay later: experimental manipulation of body mass reveals trade-offs between immune function, reproduction and survival. Front Zool 10:77.

Houston A.I. and J.M. McNamara. 1993. A theoretical investigation of the fat reserves and mortality levels of small birds in winter. Ornis Scand 24:205-219.

Houston A.I., J.M. McNamara, Z. Barta, and K.C. Klasing. 2007. The effect of energy reserves and food availability on optimal immune defence. Proc R Soc B 274:2835-2842.

Howitz J.L. 1981. A population study of the black-capped chickadee. University of Minnesota, Minneapolis.

Karasov W.H. 1982. Digestive plasticity in avian energetics and feeding ecology. Pp. 61-84 in C. Carey, ed. Avian energetics and nutritional ecology. Chapman \& Hall, New York.

Karasov W.H., M.C. Brittingham, and S.A. Temple. 1992. Daily energy and expenditure by black-capped chickadees (Parus atricapillus) in winter. Auk 109:393-395.

Killpack T.L., E. Carrel, and W.H. Karasov. 2015. Impacts of short-term food restriction on immune development in altricial house sparrow nestlings. Physiol Biochem Zool 88:195-207.

King M.O and D.L. Swanson. 2013. Activation of the immune system incurs energetic costs but has no effect on the thermogenic performance of house sparrows during acute cold challenge. J Exp Biol 216:2097-2102.

Klasing K.C. 2004. The costs of immunity. Acta Zool Sin 50: 961-969.

Langhans W. 2000. Anorexia of infection: current prospects. Nutrition 16:996-1005.

Lee K.A. 2006. Linking immune defenses and life history at the levels of the individual and the species. Integr Comp Biol 46:1000-1015.

Lehikoinen E. 1987. Seasonality of the daily weight cycle in wintering passerines and its consequences. Ornis Scand 18:216-226.

Lewden A., M. Petit, M. Milbergue, S. Orio, and F. Vézina. 2014. Evidence of facultative daytime hypothermia in a small passerine wintering at northern latitudes. Ibis 156:321-329.

Lochmiller R.L. and C. Deerenberg. 2000. Trade-offs in evolutionary immunology: just what is the cost of immunity? Oikos 88:87-98.

Love O.P., K.G. Salvante, J. Dale, T.D. Williams, A.E.Y. Michalakis, and E.M.C. Whitlock. 2008. Sex-specific variability in the immune system across life-history stages. Am Nat 172:E99-E112.
Martin L.B., Z.M. Weil, and R.J. Nelson. 2008. Seasonal changes in vertebrate immune activity: mediation by physiological tradeoffs. Philos Trans R Soc B 363:321-339.

Matson K.D., R.E. Ricklefs, and K.C. Klasing. 2005. A hemolysis-hemagglutination assay for characterizing constitutive innate humoral immunity in wild and domestic birds. Dev Comp Immunol 29:275-286.

McNamara J.M. and A.I. Houston. 1990. The value of fat reserves and the tradeoff between starvation and predation. Acta Biotheor 38:37-61.

Merchant M., T. Hammack, P. Sanders, and J. Dronette. 2006. Rapid and inexpensive method for the spectroscopic determination of innate immune activity of crocodilians. Spectrosc Lett 39:337-343.

Millet S., J. Bennett, K.A. Lee, M. Hau, and K.C. Klasing. 2007. Quantifying and comparing constitutive immunity across avian species. Dev Comp Immunol 31:188-201.

Noreen E., S. Bourgeon, and C. Bech. 2011. Growing old with the immune system: a study of immunosenescence in the zebra finch (Taeniopygia guttata). J Comp Physiol B 181:649656.

Owen J.C. 2011. Collecting, processing and storing avian blood: a review. J Field Ornithol 82:339-354.

Owen-Ashley N.T. and J.C. Wingfield. 2007. Acute phase responses of passerine birds: characterization and seasonal variation. J Ornithol 148:583-591.

Pap P.L., C.I. Vágási, J. Tökölyi, G.A. Czirják, and Z. Barta. 2010. Variation in haematological indices and immune function during the annual cycle in the great tit Parus major. Ardea 98: 105-112.

Ramsay S.M., D.J. Mennill, K.A. Otter, L.M. Ratcliffe, and P.T. Boag. 2003. Sex allocation in black-capped chickadees Poecile atricapilla. J Avian Biol 34:134-139.

Sköld-Chiriac S., A. Nord, M. Tobler, J.Å. Nilsson, and D. Hasselquist. 2015. Body temperature changes during simulated bacterial infection in a songbird: fever at night and hypothermia during the day. J Exp Biol 218:2961-2969.

Smits J.E., G.R. Bortolotti, and J.L. Tella. 1999. Simplifying the phytohaemagglutinin skin-testing technique in studies of avian immunocompetence. Funct Ecol 13:567-572.

StatSoft. 2003. STATISTICA (data analysis software system). StatSoft, Tulsa, OK.

Witter M.S. and I.C. Cuthill. 1993. The ecological costs of avian fat storage. Philos Trans R Soc B 340:73-92.

Witter M.S., J.P. Swaddle, and I.C. Cuthill. 1995. Periodic food availability and strategic regulation of body mass in the European starling, Sturnus vulgaris. Funct Ecol 9:568-574. 
Copyright of Physiological \& Biochemical Zoology is the property of University of Chicago Press and its content may not be copied or emailed to multiple sites or posted to a listserv without the copyright holder's express written permission. However, users may print, download, or email articles for individual use. 